\title{
KARAKTERISTIK DAN FUNGSI BAHASA IKLAN BISNIS LAYANAN APLIKASI CHATTING DI YOUTUBE
}

\author{
Rose Junieles $^{1)}$, Sarifah Firda Arindita ${ }^{2)}$ \\ ${ }^{1}$ Institut Agama Islam Negeri Surakarta \\ email: mbkrosejunia28@gmail.com \\ ${ }^{2}$ Institut Agama Islam Negeri Surakarta \\ email: sarifahfirda@gmail.com
}

\begin{abstract}
Abstrak
Karakteristik bahasa termasuk juga dalam ragam bahasa atau keunikan bahasa yang dimiliki oleh penuturnya, begitu juga fungsi bahasa, bahasa memiliki fungsi sebagai alat komunikasi antar penutur. Karakteristik dan fungsi bahasa termasuk kedalam variasi bahasa. Variasi bahasa di pengaruhi oleh individu dalam suatu spesies saat berinteraksi dengan orang lain, sehingga adanya variasai bahasa ini merupakan hal yang wajar dalam berbahasa. Tujuan dari penelitian ini adalah menganalisis wujud karakteristik dan fungsi bahasa yang ada pada iklan aplikasi chatting di Youtube. Penelitian ini penting dilakukan, karena dalam iklan yang muncul di Youtube sebenarnya memiliki karakteristik dan fungsi bahasa mereka sendiri untuk menarik perhatian para penikmat aplikasi. Serta menjadi manfaat bagi pembaca untuk mengetahui variasi bahasa yang dipakai dalam iklan. Metode dalam penelitian ini yaitu deksiptif kualitatif dengan pendekatan sosiolingistik. Data dari penelitian yaitu iklan aplikasi chatting yang ada di Youtube dan direkam lalu dianalisis. Teknik pengumpulan data yang digunakan dalam penelitian merupakan teknik pengamatan dan catat. Data diperoleh dengan cara mengamati iklan yang terdapat di Youtube kemudian mencatat data iklan yang ingin diteliti. Hasil dari penelitian ini menujukan bahwa adanya karakteristik bahasa pada iklan bisnis aplikasi chatting di youtube seperti karakteristik bahasa daerah, karakteristik bahasa gaul dan karakteristik bahasa asing. Adapun fungsi bahasanya seperti fungsi informasi, fungsi ekspresif dan fungsi direktif.
\end{abstract}

Kata Kunci: iklan, chatting, karakteristik bahasa, fungsi bahasa, youtube.

\begin{abstract}
Characteristics of language are included in the variety of languages or the uniqueness of the language owned by the speaker, as well the function of language, language has a function as a means of communication between speakers. Characteristics and functions of language are included in language variations. Language variations are influenced by individuals in a species when interacting with others, so the existence of language variations is a natural thing in language. The purpose of this study is to analyze the characteristics and functions of the language contained in chat application advertisements on Youtube. This research is important to do, because the ads that appear on Youtube actually have the characteristics and functions of their own language to attract the attention of application lovers. As well as being a benefit for readers to find out the variations in the language used in advertisements. The method in this study is a qualitative detective with a sociolingistic approach. The data from this research is an ad chat application on Youtube and recorded and analyzed. Data collection techniques used in research are observation and note taking techniques. The data is obtained by observing the advertisements on Youtube then recording the ad data that you want to study. The results of this study indicate that there are language characteristics in business chat applications on YouTube such as local language characteristics, slang characteristics, and foreign language characteristics. Language functions such as information functions, expressive functions and directive functions.
\end{abstract}

Keywords: advertisement, chatting, language characteristics, function of language, youtube.

\section{PENDAHULUAN}

Setiap bahasa memiliki karakteristik yang berbeda-beda. Namun dalam menyampaikan informasi, seseorang pasti akan menggunakan bahasa sebagai media penyampaiannya. Bahasa yang digunakan pun beragam dan banyak variasinnya. Bahasa merupakan alat komunikasi yang memang digunakan dalam berujar dan berkomunikasi dengan orang lain. Dengan bahasa, seseorang dapat mewakilkan kegiatan atau peristiwa yang ingin dilakukan dalam bentuk kalimat. Menurut Abdul Chaer dan Agustina (2004: 17) informasi yang disampaikan merupakan suatu ide, gagasan, keterangan, atau pesan sedangkan alat yang digunakan dapat berupa simbol atau lambang seperti bahasa berupa tanda-tanda. Hal ini 
dapat membuktikan bahwa dalam berujar atau berbahasa untuk menyampaikan informasi seseorang harus menggunakan bahasa yang sebelumnya sudah dipikirkan sedemikian rupa agar mudah dipahami dan menarik perhatian orang lain.

Bahasa yang dikemas sedemikian rupa inilah menjadikan suatu hal terlihat lebih menarik dan banyak diperhatikan. Contohnya saja pada bahasa ujaran yang sekarang banyak muncul di media-media sosial entah itu youtube, facebook, twitter, instagram dan lain sebagainya. Namun tidak bisa dipungkiri media komunikasi elektronik seperti televisi dan radio juga berperan penting dalam perkembangan bahasa ujaran yang ada. Hal ini bertujuan untuk menarik perhatian penonton atau pendengar serta membuat mereka penasaran. Biasanya bahasa yang menarik ini banyak ditemukan pada iklan-iklan yang ada di media sosial. Karena bertujuan memikat hati pelanggan, maka para produsen mencoba mengolah kemasan dan tentunya bahasa penawaran yang digunakan agar lebih menarik.

Kemenarikan ini membuktikan bahwa bahasa memiliki fungsi penting dalam memberikan informasi yang ingin disampaikan. Karena sejatinya fungsi bahasa itu sangat beragam. Fungsi bahasa lebih mengarah untuk keperluan apa saja bahasa yang digunakan manusia, Sudaryanto (dalam Aslinda dan Syafyahya, 2010 : 89). Pada saat seseorang memasarkan produk inilah fungsi bahasa digunakan, menempatkan bahasa yang sekiranya pantas untuk disajikan kepada penonton atau pendengar. Namun hal ini berfungsi bukan untuk pendengar saja, akan tetapi dapat berfungsi untuk pembicara atau pengungkap yang ingin menyampaikan informasi dan membawakan bahasa yang digunakan dengan baik agar pesan dapat ditangkap oleh pendengar. Dengan bahasa yang baik dan beragam. Beragam keunikan yang coba diciptakan oleh pengungkap.

Ragam bahasa yang digunakan dalam media sosial atau iklan tentunya tidak sembarangan dan harus ada ciri-ciri yang dipenuhi. Salah satu cirinya seperti harus menggunakan kalimat persuasif untuk menarik perhatian orang lain, menggunakan kata-kata diksi, serta penggunaan bahasa yang tepat dan mudah dipahami. Walaupun ragam bahasa yang digunakan dalam media online kebanyakan menggunakan bahasa informal atau tidak resmi akan tetapi tetap ada kriteriakriteria yang diperlukan. Menurut Sugono (dalam Sorta, 2004: 3) ragam bahasa dapat dibedakan atas tiga kriteria, yaitu (1) media yang digunakan, (2) latar belakang penutur, dan (3) pokok persoalan yang dibicarakan. Ketiga kriteria tersebut mewakili ragam bahasa yang ada, walaupun sebenarnya masih ada pembagian-pembagian lagi.

Penggunaan ragam bahasa yang ada dimedia sosial inilah memicu para produsen berlomba-lomba menciptakan hal-hal unik untuk produk pasaran mereka. Contohnya pada iklan yang kadang kita lihat pada televisi, channel youtube, dan media sosial yang lain. Kehadiran media sosial dalam kehidupan masyarakat membawa dampak besar, salah satunya memudahkan manusia untuk saling berkomunikasi dalam jarak jauh secara cepat serta sebagai wadah bersosialisasi dan berinteraksi (Indersari dkk, 2019: 38). Dengan kecanggihan zaman sekarang yang sangat mencengangkan membuat semua orang berlomba-lomba mengembangkan kreatifitas mereka melalui bahasa yang mereka tampilkan dalam iklan tersebut. Bahasa yang bervariasi coba mereka hadirkan, namun tetap dengan kaidah kebahasaan yang ada. Variasi dalam artian disini yaitu penggunaan atau perubahan wujud penggunaan bahasa sesuai konteksnya saja namun tetap memperhatikan kaidah kebahasaan yang ada. Walaupun pada iklan bahasa yang digunakan kebanyakan informal namun kaidah kebahasaan tetap diperhatikan.

Iklan yang dibahas disini lebih kepada akun youtube yang hampir setiap orang pasti melihatnya pada saat memulai playlist. Ada beberapa iklan yang memang muncul dan mempromosikan produk mereka. Karena pada umunya iklan yang ada pada youtube 
merupakan iklan komersil yang sudah di siapkan oleh pihak google. Setiap akun youtube yang sudah dimasuki iklan maka akun tersebut sudah mendapatkan reward atau hadiah. Akun-akun ini menjadi media untuk mencari rezeki oleh sebagian orang. Banyak iklan yang berisi tentang aplikasi, jasa dan pesan-pesan yang dimuat untuk masyarakat. Disini aplikasi merupakan perangkat lunak yang dibuat oleh programer yang beroperasi pada sistem tertentu yang dikembangkan untuk melakukan perintah tertentu.

Pada dasarnya aplikasi dikembangkan menjadi tiga. Pertama aplikasi desktop atau aplikasi yang hanya tersedia di komputer dan laptop, kedua aplikasi web atau apikasi yang hanya bisa di jalankan bila ada koneksi internet dan ketiga aplikasi mobile atau aplikasi yang hanya bisa dijalankan lewat smartphone. Saat ini banyak sekali aplikasi media sosial dengan beragam bentuknya mulai dari forum, situs jejaring sosial, berbagai media atau opini memberikan pengguna untuk berinteraksi sekaligus berpartisipasi dalam kegiatan sosial virtual (Jumiatul dan Sri, 2015)

Peran media sosial disini sebagai pemasaran produk-produk yang mereka jajakan, memiliki media sosial sangat penting karena peran media sosial sekarang ini sebagai media komunikasi. Sebab dengan berkomunikasi kita akan mendapatkan berbagai jenis informasi yang menguntungkan baik itu dari segi pemasaran produk barang dan jasa. Menurut Morrisan (2007) komunikasi merupakan upaya yang menjadikan seluruh kegiatan pemasaran dan produksi untuk sebuah perusahaan yang dimana perusahaan tersebut akan mendapatkan citra yang baik dan bersifat konsisten. Keberadaan media sosial memang membantu dalam urusan mencari informasi, pemasaran, bahkan media untuk komunikasi seperti aplikasi chatting yang sangat banyak peminatnya dan memiliki keunikan yang berbeda-beda.

Keberadaan media sosial seperti aplikasi chatting juga kerap membantu dan menarik perhatian banyak orang, selain karena kemudahaanya aplikasi-aplikasi tersebut dapat menjangkau di berbagai pelosok daerah, kota bahkan negara. Berbagai aplikasi tersebut contohnya Mi Chat, Whatsapp, Kakaotalk, dan Line. Selain karena kegunaan aplikasi, promosi yang menarik pada youtube membuat sebagian besar orang ingin menggunakan aplikasi tersebut. Penggunaan bahasa yang menarik dengan susunan yang unik membuat banyak orang tertarik. Penggunaan bahasa seperti ini juga mempengaruhi kelarisan dari suatu produk atau aplikasi. Penggunaan bahasa yang beragam dan disusun dengan baik menjadi faktor pemicu ketertarikan seseorang untuk mencoba bahkan mengunduh aplikasi tersebut.

Kehadiran internet membawa dampak besar dalam perkembangan berbagai aplikasi di dunia maya. Internet merupakan suatu jaringan komputer yang saling terhubung dengan sistem global, dan dipandang serius sebagai gudangnya informasi. Tidak bisa dipungkiri dengan adanya internet menjadi salah satu sumber daya informasi yang sangat pontensial untuk mempermudah sistem kehidupan (Trafena Talika, 2016). Perbedaan variasi berdampak pada perbedaan penghasilan seseorang pula. Ternyata kemenarikan yang dihasilkan dari bahasa mempengaruhi berbagai macam segi.

Penelitian tentang karakteristik bahasa iklan pada media sosial terutama aplikasi chatting di youtube juga dirasa penting dilakukan, karena masih sedikit yang menyadari pentingnya bahasa dalam pemasaran suatu produk. Keunikan model visual dalam iklan menjadi daya tarik tersendiri bagi konsumen sehingga hal tersebut berpengaruh terhadap daya beli konsumen terhadap sebuah produk. Selain itu penelitian ini juga dirasa berguna sebagai penambah wawasan terhadap variasi bahasa yang digunakan oleh para produsen untuk memasarkan aplikasinya.

Sebelumnya juga ada beberapa peneliti serupa tentang bahasa yang ada pada iklan oleh Sorta Hutahaen dalam jurnal Ilmu Budaya volume 1 no 1 tahun 2004 dengan judul "Analisis Bahasa Iklan Pada Majalah Kartini” 
lalu oleh Dian Lukiana dalam bentuk skripsi Universitas Muhammadiyah Surakarta dengan judul "Analisis Variasi Bahasa Pada Rubrik Kriiing Surat Kabar Solopos Kajian Sosiolinguistik, dan ketiga oleh Yetty Dompas dalam bentuk skripsi Universitas Sam Ratulangi dengan judul "Karakteristik Pemakaian Bahasa Laras Iklan Pada Jejaring Sosial Instagram" Ketiganya sudah meneliti tentang variasi bahasa dengan pembahasan yang lumayan spesifik, namun pada penelitian ini lebih ditekankan pada karakteristik bahasa iklan pada youtube. Karena untuk analisis tersebut masih jarang sekali diteliti, apalagi layanan aplikasi chatting memiliki pengguna yang lumayan banyak dan sangat menaik untuk diteliti. Kemenarikan ini yang membuat peneliti memilih meneliti karakteristik bahasa iklan pada layanan aplikasi. Tujuan penelitian yang ingin dicapai adalah karakteristik bahasa iklan dan juga fungsi bahasa pada iklan yang terdapat di Youtube.

Dalam penelitian ini peneliti menggunakan pendekatan sosiolinguistik sebagai upaya dalam membedah pengaruh apa saja yang membuat bahasa dalam iklan aplikasi chatting yang ada di youtube terlihat lebih unik serta menarik perhatian banyak orang. Sosiolinguistik dipilih karena merupakan kajian ilmu yang mempelajari pengaruh baik budaya terhadap suatu bahasa karena terkadang didalam suatu iklan ada beberapa budaya yang coba dimasukan dan dipadu padankan untuk membuat sesuatu yang beda. Sosiolinguistik adalah ilmu yang bersifat interdisipliner, gabungan dari sosiologi dan linguistik. Bram \& Dickey (dalam Paul 2002:9) menyatakan bahwa sosiolinguistik mengkhususkan kajiannya pada bagaimana bahasa berfungsi ditengah masyarakat.

\section{KAJIAN LITERATUR}

Penelitian ini menggunakan pendekatan sosiolinguistik. Sosiolongistik merupakan salah satu ilmu yang mempelajari bahasa. Sosiolinguistik merupakan kajian lingustik yang bersifat antardisiplin karena gabungan dari dua ilmu yaitu sosiologi dan linguistik. Sosiolinguistik adalah bagian dari linguistik yang berhubungan dengan bahasa sebagai gejala sosial dan gejala budaya sehingga budaya masuk dalam bahasa, Tudgill (dalam Giyoto, 2013: 7). Sedangkan menurut Booiji (dalam Rafiek, 2005:2) sosiolinguistik merupakan salah satu cabang linguistik yang mempelajari faktor-faktor sosial yang berperan sebagi bahasa dalam pergaulan. Dalam penelitian ini melibatkan bahasa yang beragam dan digunakan masyarakat untuk membuat suatu kalimat yang terkesan unik dan menarik. sosiolinguistik muncul berdasarkan asumsi bahwa bahasa sendiri bukanlah monolitik dan homogen, tetapi bahasa bersifat heterogen dan tentunya bervariasi.

Bahasa memiliki fungsi sebagai pengekspresian diri hal ini bisa dalam artian tentang menyampaikan gagasan, pikiran, perasaan dan pengalaman bahasa juga memiliki fungsi sebagi alat kontrol sosial, dalam hal ini bahasa memiliki fungsi sebagai alat kontrol yang mengatur berbagai kegiatan atau aktivitas sosial seseorang. Aktivitas sosial akan berjalan dengan baik bila kita bisa mengontrol berbahasa kita terhadap orang lain, dan dalam konteks bahasa Indonesia, bahasa mmilki fungsi sebagi bahasa nasional yang sudah di atur dalam Undang-Undang Dasar 1945. Sedangkan Leech (dalam Hutahaean 2004 : 25) berpendapat bahwa fungsi bahasa ada lima yaitu fungsi informasi untuk memberikan informasi, fungsi ekspresif untuk menyatakan gambaran, fungsi direktif untuk mengarahkan sikap dan tingkah laku orang lain, fungsi fatik untuk mempererat kesinambungan dan fungsi estetik untuk menyatakan tentang keindahan.

Karakteristik bahasa ini dapat dibedakan berdasar media pengantarnya dan berdasarkan situasi penutur, berdasarkan media pengantarnya bahasa dibedakan atas bahasa lisan dan bahasa tulis sedangkan berdasarkan situasi penutur bahasa dibedakan atas bahasa formal dan nonformal. Dalam penelitian ini, peneliti akan mengelompokkan bahasa yang 
digunakan dalam iklan. Karena setiap iklan pasti memiliki bahasa yang berbeda-beda untuk menarik minat masyarakat. Sebagai objek sosiologi, bahasa tidak dilihat atau didekati sebagai bahasa, sebagaimana dilakukan oleh linguistik umum, melainkan dilihat atau didekati sebagai sarana interaksi atau komunikasi didalam masyarakat manusia (Abdul Chaer dan Agustina, 2004: 3). Karena setiap kegiatan yang dilakukan masyarakat tidak akan terlepas dari penggunaan bahasa itu sendiri.

Variasi bahasa adalah ragam bahasa atau keunikan bahasa yang dimiliki oleh penuturnya. Variasi bahasa di pengaruhi oleh individu dalam suatu spesies saat berineraksi dengan orang lain, sehingga adanya variasai bahasa ini merupakan hal yang wajar dalam berbahasa. Karena setiap orang pasti memiliki keunik dan dan ciri khas tersendiri dalam berbahasa menurut Allan Bell (dalam Coupland dan Adam, 1997: 240) prinsip dari variasi bahasa adalah penutur tidak harus sama dalam cara mengucapkan bahasa karena setiap individu punya cara tersendiri untuk menyampaikan bahasa yang ada. Sedangkan menurut Nababan (1993:13) penyebab timbulnya variasi bahasa ada empat faktor yang memengaruhi, yang pertama adalah daerah yang berbeda, yang kedua keadaan sosial yang berbeda, yang ketiga situasi berbahasa penutur, dan yang terakhir adalah zaman atau masa kemasa.

Iklan merupakan salah satu bentuk dari komunikasi dalam pemasaran suatu produk, iklan menjadi media komunikasi antara produsen dan konsumen. Produsen menggunakan iklan ini sebagai media untuk menawarkan suatu produk, barang dan jasa agar memikat para konsumen. Menurut Jefkins (1997 :15) mangatakan bahwa iklan merupakan penjualan informasi yang menyeluruh, sehingga iklan bisa dikatakan media komunikasi lanjutan untuk mendapatkan sebuah informasi, oleh sebab itu iklan harus memiliki daya tarik yang kuat untuk memikat para konsumen untuk memilih, membeli dan menggunakan produk yang sudah diiklankan.

Menurut Kertamukti (2016 :64) mengkatakan bahwa iklan adalah sebuah pesan yang menawarkan suatu produk, barang dan jasa yang ditujukan untuk masyarakat melalui media. Disini selain iklan sebagai bentuk informasi tidak lanjut, iklan juga memiliki sifat mempengaruhi masyarakat sehingga sebagian orang akan merubah pemikiran terhadap produk yang sedang dipasarkan dan hal ini sangat menguntungkan pihak produsen atau penghasil suatu produk, barang dan jasa karena mampu menunjang penjualan baik itu dalam jangka panjang maupun jangka pendek.

Aplikasi merupakan sebuah program yang dibuat oleh programer yang ditujukan untuk melakukan suatu tugas tertentu. Menurut Kadir (2008 : 3) aplikasi merupakan sebuah program siap pakai yang di rancang dan dibuat untuk menjalankan sebuah tugas guna mempermudah kegiatan atau aktivitas masyarakat yang berkaitan dengan aplikasi tersebut. sedangkan menurut Supriyanto (2005:2) aplikasi adalah program yang memiliki aktivitas pemrosesan perintah yang digunakan untuk menjalankan permintaan pengguna.

Maka pengkajian dilakukan pada penelitian ini merupakan bahasa yang sebenarnya terdapat dalam kegiatan kita sehari-hari namun diolah lagi agar menjadi sesuatu yang beda dan dapat menarik perhatian. Karena fenomenafenomena bahasa seperti ini sebenarnya sangat penting dan jarang disadari. Serta penggunaan sosiolinguistik oleh peneliti dalam penelitian wujud variasi bahasa ujaran pada iklan aplikasi chatting di media youtube dimaksudkan untuk mengungkapkan variasi apa saja yang ada dalam penggunaan bahasa didalamnya.

\section{METODE PENELITIAN}

Penelitian ini dilakukan dengan metode deksiptif kualitatif, merupakan metode pengumpulan data yang mengungkapkan kejadian atau fakta, keadaan fenomena, variabel dan keadaan yang terjadi saat penelitian berlangsung dengan memberikan 
kejadian yang sebenarnya. Sedangkan menurut Nazir (1988: 63) dalam bukunya yaitu "Contoh Metode Penelitian" metode deskriptif merupakan suatu metode dalam meneliti status sekelompok manusia, suatu objek, suatu set kondisi, suatu sistem pemikiran ataupun suatu kelas peristiwa pada masa sekarang.

Tujuan penelitian ini mendeskripsikan datadata berupa bahasa yang terdapat didalam youtube. bahasa yang bervariasi bertujuan untuk menjelaskan latar belakang dibuatnya video tersebut pada masanya, atau fenomena yang sedang hits pada saat itu yang coba dimasukan kedalam iklan. Data yang digunakan merupakan berbagai variasi ujaran yang terdapat didalam iklan aplikasi chatting yang ada di youtube. Menurut Chairi (dalam Oktavia, 2018: 319) metode deskriptif kualitatif merupakan metode pengkajian atau metode penelitian yang dilaksanakan dengan menggunakan pendeskripsian berupa kata-kata dan tidak menggunakan paparan angka.

Subjek dalam penelitian ini adalah berbagai wujud variasi ujaran yang ada di dalam aplikasi chatting di youtube. Data berupa frasa atau kalimat variasi bahasa yang digunakan oleh para pelaku dalam iklan, baik sendiri maupun dengan lawan bicaranya yang ada di dalam video iklan tersebut. Objek penelitian ini yaitu berbagai variasi bahasa ujaran yang ada pada iklan dalam media sosial edisi 5 tahun terakhir.

Analisis data dengan cara interaktif yang bertahap dari reduksi data seperti memilih iklan yang pantas untuk tampilkan dan di catat dengan merangkum hal-hal pokok, lalu tahap selanjutnya model data atau data display pada tahap ini data mulai dikategorikan kedalam jenis-jenis yang sudah ditentukan dan tahap akhir merupakan tahap verifikasi kesimpulan pada tahap ini data yang sudah ada tersebut di verifikasi agar dapat menjawab rumusan masalah. Setelah itu dianalisis menggunakan metode yang sudah dipilih dengan menjelaskan berbagai alasannya.

\section{HASIL DAN PEMBAHASAN}

Iklan pada media sosial merupakan sesuatu yang menarik, sebagai wahana penyampaian pemasaran suatu produk dan pengenalannya. Dalam iklan, aktor yang menjadi penutur mencoba menyampaikan semenarik mungkin dengan konsep yang telah ditentukan dan disepakati atau mungkin tampilan lainnya yang dibuat sedemikian rupa agar mencolok dan mengundang rasa penasaran siapapun yang melihatnya. Penutur mencoba berkomunikasi dengan para pendengar dan pengamat yang melihat iklan. Tentunya bahasa yang digunakan dibuat menarik, padat, jelas namun maksud yang ingin disampaikan tetap jelas

Dalam iklan tentunya memiliki karakter kebahasaan yang berbeda-beda, langkah pertama dalam menganalisis data adalah menyimak iklan secara terulang-ulang sampai menemukan karakteristik bahasa dalam iklan tersebut. Kali ini peneliti memilih dua macam analisis pertama tentang karakteristik bahasa pada iklan dan kedua fungsi bahasa pada iklan.

a. Karakteristik Bahasa

Berdasarkan hasil dan pembahasan karakteristik bahasa iklan ada tiga, pertama karakteristik bahasa daerah kedua karakteristik bahasa gaul dan ketiga karakteristik bahasa asing pada iklan aplikasi Mi Chat, Tinder, KakaoTalk, BBM dan Line. Adapun penjelasannya seperti dibawah ini

1) Karakteristik bahasa daerah dalam iklan aplikasi Chatting

\begin{tabular}{cll}
\hline No & Bahasa Sunda & \multicolumn{1}{c}{ Artinya } \\
\hline 1 & Aa atau Aang & Kakak laki-laki \\
\hline 2 & Eneng & Sapaan untuk wanita \\
\hline 3 & Jurik & Hantu \\
\hline 4 & Ambek & Marah \\
\hline 5 & Hampura & Maaf \\
\hline 6 & Hareudang & Gerah \\
\hline 7 & Orok & Bayi \\
\hline
\end{tabular}

Dalam iklan Tinder ini. pihak Tinder Indonesia berkolaborasi dengan youtuber seperti bujang rimba. Dalam iklan yang pertama ini menampilkan aktor 1 yaitu seorang wanita yang berdiri ditengah hutan malammalam dan sedang kedinginan, lalu muncul aktor 2 seorang laki-laki sang pawang hantu, dan ketika itu aktor 1 ketakutan hingga 
akhirnya muncul aktor 3 sebagai seorang lakilaki yang melindunginya.

Aktor 1 : Duh, Bandung dingin bangeut nyet. Eh aduh aduh

Aktor 2 : Neng, liat sesuatu ga?

Aktor $1:$ Hah? Apaan aa?

Aktor 2 : Tadi Jurik saya ada yang lepas

Aktor 1 : Hah? Aduh serem banget, gak liat aa

Aktor 2: Oh gak liat ya, makasih ya

Aktor 1: Aduh serem bangeut, dingin lagi

Aktor 3 : Neng Revi yah?

Aktor $1:$ Iyah

Aktor 3 : Oia bener inimah, yang barusan Match ya?

Aktor 1 : Iya

Aktor 3 : Udah jangan takut neng, hantu mah takut semua sama Aang!

Dalam kalimat tersebut ada beberapa kata yang menggunakan bahasa sunda seperti Neng atau Eneng yang berarti sapaan untuk wanita, Aa atau Aang yang berarti kakak laki-kali, Jurik yang berarti hantu, dan ada kata sisipan mah yang kental dengan karakteristik bahasa Sunda. Pada iklan aplikasi Tinder yang bekerjasama dengan bujang rimba dan merupakan youtuber lokal, mereka mencoba memasukan bahasa daerah kedalam iklan mereka. Untuk mengenalkan bahasa daerah kepada para penonton dengan bahasa-bahasa daerah yang masih dasar seperti sapaan diatas.

Iklan ini juga dipublikasikan pada tanggal 4 Desember 2019 dengan tema horor karena pada saat itu sedang hits acara-acara bertemakan paranormal dan penelusuran ke tempat-tempat yang misterius dengan hal-hal gaib. Namun Tinder tetap mencoba mengkolaborasikan dengan aplikasi mereka agar diminati. Selain Tinder yang menggunakan karakteristik bahasa daerah dalam iklannya serta mengaitkannya dengan fenomena yang ada pada saat itu, adapula aplikasi lain seperti Shopee yang merupakan aplikasi belanja online membuat iklan dan berkolaborasi dengan penyanyi dangdut Didi Kempot, dalam iklannya Didi Kempot mempromosikan aplikasi Shopee dengan bahasa Jawa yang didangdutkan karena pada saat yang bersamaan lagu dangdut sedang hits dikalangan manapun. Bisa dilihat contohnya pada link ini https://youtu.be/EYTaVclajAU.

2) Karakteristik bahasa gaul dalam aplikasi Chatting

\begin{tabular}{clll}
\hline No & Bahasa Gaul & & Artinya \\
\hline 1 & Gue & Aku & \\
\hline
\end{tabular}

\begin{tabular}{lll}
\hline 2 & Lu & Kamu \\
\hline 3 & Nebeng & Ikut serta \\
\hline 4 & Boong & Bohong \\
\hline 5 & Bro & Sapaan untuk laki-laki \\
\hline 6 & Sis & Sapaan untuk perempuan \\
\hline 7 & Santuy & Santai \\
\hline
\end{tabular}

Aplikasi Mi Chat ini merupakan apikasi baru yang hadir dengan kemasan yang berbeda daripada aplikasi Chatting yang lain.

Ada beberapa varian iklan dalam aplikasi ini yang pertama dipublikasikan pada tanggal 23 Oktober 2019 berisikan tentang aktor 1 seorang pria yang diselingkuhkan oleh pacarnya dan terlihat marah kepada aktor 2 seorang wanita yang baru saja mengakhiri hubungannya namun sudah mendapatkan pasangan baru. Namun Aktor 1sudah mendapatkan pasangan baru yaitu seorang wanita sebagai aktor 3, dengan bantuan aplikasi Mi Chat.

Aktor 1 : Gila lu ya, kita baru putus Sa, gue aja belum bisa ngelupain lu

Aktor 2: Ya iya lah secara, kan gue cantik

Aktor 1 : Tapi boong

Aktor 3 : Hai baby

Aktor 1 : Hai baby

Aktor 2 : Kok kamu cepet banget dapat cewek baru sih?

Aktor 1 : Ya iya lah, kan gue pakai aplikasi $M i$ Chat, aplikasi $M i$ Chat bisa pakai fitur trending chat jadi bisa lihat orang-orang tertentu

Aktor 3 : Kalau gitu udah dulu ya, gue sama bayu mau ngedate dulu

Aktor 2 : Eh tunggu download nya gimana?

Aktor $1 \& 3$ : Klik aja link dibawah ini untuk download!

Selanjutnya ada iklan kedua dengan aplikasi yang sama dan dipublikasikan pada tanggal 23 Oktober 2019, berisi tentang aktor 1 seorang wanita yang sedang kesusahan mencari kendaraan untuk pulang lalu datang aktor 2 seorang laki-laki menggunakan mobil yang membantunya.

Aktor 1 : Tolong, gak ada kendaraan buat pulang ada yang lagi di Campelas gak? Nebeng dong.

Aktor 2 : Hai cantik, tunggu aku lima menit lagi aku sampai

Aktor 1 : Makasih ganteng, aku tunggu disini ya

Aktor 2 : Nih barang banyak banget?

Aktor 1 : Iya nih makanan enak semua, besok ada party di rumah bisa datang gak? 
Aktor 2: Oh bisa

Aktor 1 : Oke deh tepat waktu loh!

Aktor 2 : Oke-Oke

Selain itu ada lagi iklan Mi Chat yang lain dan baru saja dipublikasikan pada tanggal 20 Februari 2020. Berisi tentang aktor 1 seorang laki-laki yang sedang melihat wanita cantik yang disukainya, ada aktor 2 sebagai wanita yang ditaksir oleh aktor 1 dan aktor 3 sebagai laki-laki teman kantor dari aktor 1 .

Aktor 1 : Woy, tadi tuh gue abis ketemu cewek cantik dikafe samping kantor lucu banget tipe gue banget pokoknya. Haduh tapi gue bingung banget ni kenalannya gimana ya caranya.

Aktor 3 : Kayanya dia kerjanya deket-deket sini deh, coba lu pake Mi Chat aja.

Aktor 1 : Mi Chat? Apaan tu?

Aktor 3 : Mi Chat nih aplikasi, nih liat nih. Nih jadi lu tinggal cari talk ni liat terus klik nearby tu liat.

Aktor 1 : Eh ini kan cewek yang gue suka, kok lu yang ngambil.

Sebenarnya masih ada beberapa iklan $M i$ Chat lainnya, dan jika dilihat iklan pada aplikasi ini ditujukan untuk kalangan remaja karena semuanya menggunakan bahasa gaul. Mereka menggunakan bahasa-bahasa yang mudah diterima dan dimengerti kalangan remaja tentunya. Perubahannya hanya pada aplikasi tambahan yang mereka gunakan. Mulai dari contoh iklan yang pertama sampai ketiga, mereka menggunakan aplikasi tambahan yaitu sejenis lokasi terdekat. Jadi pelanggan bisa mencari pasangan dengan mengaktifkan lokasi terdekat, ini berkaitan dengan hits nya kabar zonasi pada jangka waktu iklan ini dimunculkan. Mereka mencoba menghadirkannya dalam aplikasi Mi Chat agar bisa mengetahui dan mendapatkan jodoh yang dekat.

3) Karakteristik bahasa asing dalam aplikasi

\begin{tabular}{cll}
\multicolumn{2}{l}{ Chatting } & \\
\hline No & Bahasa Asing & \multicolumn{1}{c}{ Artinya } \\
\hline 1 & Download & Unduh \\
\hline 2 & Keyword & Kata Kunci \\
\hline 3 & Upgrade & Memperbarui \\
\hline 4 & Free & Gratis \\
\hline 5 & Fun & Menyenangkan \\
\hline 6 & Chatting & Mengobrol \\
\hline
\end{tabular}

Dalam beberapa iklan chatting sering kali para pembuat iklan menggunakan bahasa asing untuk menarik penikmat aplikasi khusunya kalangan anak muda yang menyukai hal-hal berbau asing. Kalangan anak muda beranggapan bahwa hal-hal yang berbau asing itu keren dan tidak ketinggalan zaman sehingga harus dikuasai walaupun kadang malah menjadikan mereka melanggar kaidah berbahasa. Iklan aplikasi chatting yang menggunakan bahasa asing sudah tidak jarang dijumpai, namun sebagai contoh disini ada iklan aplikasi BBM atau Blackberry Massanger yang banyak sekali menggunakan fitur-fitur bahasa asing. Contoh iklan BBM yang dibacakan oleh naratornya yaitu:

"Heheiii salah kirim pesan? Tenang dengan Retract Message kamu bisa langsung hapus pesan di BBM kamu dengan teman mu, upgrade BBM kamu di BBM.com"

Dalam iklan BBM tersebut sering di jumpai bahasa asing seperti Retract Message yang berarti menarik pesan dan upgrade yang berarti memperbarui. Bahasa ini digunakan karena pada kalangan anak muda sudah tidak digunakan lagi bahasa "memperbarui" dan "menarik pesan" karena mereka sudah mengikuti zaman yang mereka anggap keren.

Selain iklan aplikasi BBM, iklan aplikasi Line juga sering menggunakan bahasa asing untuk menarik penikmat aplikasi. Contohnya yaitu:

"Dengan fitur yang lebih canggih dan metode pembayaran Pay Per Broadcast peningkatan fitur dashboard statistik. Download aplikasi terbaru dengan mengetik keyword Line Official Account"

Dalam iklan Line banyak menggunakan fitur bahasa asing seperti Pay Per Broadcast yang berarti membayar persiaran lalu dashboard statistik yang berarti statistik instrumen dan Keyword yang berarti kata kunci. Pada Line, kata-kata yang digunakan dalam bahasa asing lebih sulit dan tidak sesederhana seperti iklan aplikasi BBM karena penggunannya sudah bukan hanya kalangan anak muda lagi namun dalam beberapa kasus juga sudah digunakan oleh orang-orang dewasa.

Selanjutnya ada lagi iklan aplikasi lainnya yaitu KakaoTalk, KakaoTalk sering menyajikan iklan dengan menggunakan jargon bahasa asing contohnya: 
"Menyampaikan langsung pesan dengan

live emotikon. Fun Talk KakaoTalk"

Aplikasi KakaoTalk juga tidak luput dari pemakaian bahasa asing seperti Live yang berarti langsung dan jargonnya yang menggunakan bahasa asing Fun Talk KakaoTalk yang berarti menyenangkan berbicara dengan KakaoTalk.

Dari ketiga iklan aplikasi tersebut dapat dilihat bahwa berbagai aplikasi cenderung menggunakan bahasa asing, memang tidak bisa di pungkiri bahasa asing sangat berpengaruh dalam hal pemasaran karena sasaran mereka untuk aplikasi ini yaitu kalangan anak muda yang sangat senang dengan ragam bahasa. Fenomena bahasa yang dapat dilihat seperti alih kode campur kode yang digunakan beberapa aplikasi diatas memang bukan baru saja terjadi. Bahkan bukan hanya pada iklan aplikasi chatting saja, iklan aplikasi belanja online, makanan, kecantikan dan lainnya juga memang lebih menarik bagi penikmat atau penonton jika menggunakan bahasa asing. Sesuatu yang dari dahulu sudah dianggap keren padahal tanpa disadari itu semua malah membuat kesalahan dalam fenomena bahasa.

b. Fungsi Bahasa

Analisis fungsi bahasa ini fokus pada fungsi-fungsi bahasa yang muncul dalam setiap iklan yang sudah dipilih oleh peneliti. Beberapa aplikasi yang sudah di pilih oleh peneliti antara lain BeeTalk, KakaoTalk dan Line. Adapun penjelasannya seperti dibawah ini

1) Fungsi Informasi

(a) "Mengirim chat KakaoTalk, KakaoTalk gampang banget yang pertama pilih siapa yang mau kamu kirim, emotikon pastinya, bisa kirim foto juga loh. Mau seratus atau seribu pesan pun bebas kirim sepuasnya. Wow ini semua gratis, Free, Free, Free, Free talk KakaoTalk"

Dalam iklan KakaoTalk diatas memiliki fungsi sebagai informasi yaitu menginformasikan bahwa aplikasi tersebut gratis, untuk kirim chat menggunakan emotikon sepuasnya tanpa harus membayar.

(b) "Malu kenalan? Pakai BeeTalk, kenal orang baru semudah liat orang sekitar, pilih teman, kirim salam perkenalan dan Chatting. BeeTalk beranikan dirimu cari teman baru!"
Dalam iklan BeeTalk diatas memiliki fungsi sebagai informasi karena menginformasikan bahwa aplikasi BeeTalk mampu menambah teman baru tanpa harus malu untuk berkenalan, hanya dengan kirim salam perkenalan maka teman akan bertambah. Aplikasi tersebut dirancang untuk menambah teman baru dengan mudah dalam radius beberapa kilo meter.

2) Fungsi Ekspresif

(a) "KakaoTalk live emotikon menghubungkan dan menyatakan emosi kita secara langsung. Sampaikan salam ramadhan dengan animasi KakaoTalk. Free Talk KakaoTalk"

Dalam iklan KakaoTalk diatas memiliki fungsi sebagai ekspresif karena dapat menyatakan perasaan secara langsung, dalam ikan tersebut menyebutkan bahwa live emotikon dapat menghubungkan dan menyatakan emosi secara langsung tanpa perantara.

(b) "Secepat apa chat pakai KakaoTalk? "Hallo Kau dimana? Hahahaha" secepat penghapus itu akan melayang, cobain cepatnya chatting tanpa pending dengan Speed Booster Engine"

Dalam iklan KakaoTalk diatas memiliki fungsi sebagai ekspresif karena menyatakan keterkejutan terhadap kecepatan chatting menggunakan Speed Booster Engine. Sehingga dapat chatting tanpa khawatir tertunda dan lama.

3) Fungsi Direktif

(a) "Line openchat temukan teman baru dengan minat yang sama, temukan topik populer, direkomendasikan dan baru. Pilih identitas mu setiap openchat. Lihat seluruh riwayat obrolan. Tambah obrolan sesuai kebutuhan. Bahasa apa pun bareng siapa pun semua ada openchatnya"

Dalam iklan Line diatas memiliki fungsi sebagai direktif, karena dalam iklan diatas mengharapkan aplikasi tersebut membantu menemukan teman baru dan menemukan topik populer yang direkomendasikan. Pada iklan ini secara tidak langsung membuat pengguna aplikasi ketergantungan atau mengharapkan aplikasi untuk melakukan sesuatu seperti menemukan teman baru.

Fungsi bahasa yang digunakan dalam iklan aplikasi chatting pada youtube untuk mempromosikan produk-produk mereka berupa fungsi informasi, fungsi eksresif dan 
fungsi direktif. Fungsi tersebut sudah sesuai dengan fungsi bahasa yang dikemukakan oleh para ahli bahasa.

\section{KESIMPULAN}

Dari Karakteristik bahasa yang sudah diteliti, dapat disimpulkan bahwa dalam bahasa iklan terdapat karakteristik bahasa berupa karakteristik bahasa daerah, bahasa gaul dan bahasa asing. Karakteristik ini disesuaikan dengan fenomena yang sedang marak dan banyak terdapat didalam iklan. Iklan aplikasi chatting juga memperhatikan fenomena sekitar yang sedang hits untuk dikolaborasikan dengan aplikasi mereka sehingga para penikmat menjadi terpikat dan mencoba aplikasi tersebut.

Selain itu fungsi bahasa yang terdapat dalam iklan merupakan fungsi informasi, fungsi ekspresif dan fungsi direktif. Hal ini tentu menjadi fenomena yang sudah semakin marak menjadi karena beberapa foktor. Salah satunya seperti perkembangan zaman, semakin maju zaman yang ada maka semakin berkembang pula bahasa yang didapatkan guna menarik perhatian masyarakat dan untuk menggunakan aplikasi yang sudah dirancang dengan baik oleh para programer. Sehingga dapat disimpulkan bahwa iklan sangat memerlukan karakteristik bahasa untuk menarik perhatian masyarakat.

\section{DAFTAR PUSTAKA}

Abdul, C. L. A. 2004. Sosiolinguistik Perkenalan Awal. Jakarta: PT Rineka Cipta.

Alexander, Morrisan. 2007. Periklanan Komunikasi Pemasaran Terpadu. Jakarta: Ramdina Prakarsa.

Aslinda. Syafyahya, L. 2010. Pengantar Sosiolinguistik. Bandung: PT Refika Aditama.

Dompas, Yetty. 2017. Karakteristik Pemakaian Bahasa Laras Iklan Pada Jejaring Sosial. Manado: Universitas Sam Ratulangi.

Emzir. 2010. Metodologi Penelitian Kualitatif: Analisis Data. Jakarta: Raja Grafindo.

Giyoto. 2013. Pengantar Sosiolinguistik. Surakarta: Fataba Presss.

Hamidah, Jamiatul dan Normuliati, Sri. 2015. Analisis Tindak Tutur Endorse Di Media
Sosial Instagram. Banjarmasin : Universitas Muhammadiyah Banjarmasin.

Hutahaean, Sorta. 2004. "Analisis Bahasa Iklan Pada Majalah Kartini". Jurnal Ilmu Budaya.

Inderasari, Elen, Ferdian Achsani, dan Bini Lestari. 2019. "Bahasa Sarkasme Netizen Dalam Komentar Akun Instagram Lambe Turah". Semantik. Vol. 8 No.1.

Jefkins, Frank. 1997. Periklanan. Edisi ke tiga. Jakarta : Erlangga.

Kertamukti, R. (2016). Strategi Kreatif dalam Periklanan: Konsep Pesan, Media, Branding, Anggaran (1st ed.). Jakarta: Raja Grafindo Persada.

Nazir, M. 1988. Metode Penelitian, Ghalia Indonesia: Jakarta.

Oktavia, Wahyu. 2018. "Variasi Jargon Chatting Whatsapp Grup Mahasiswa Tadris Bahasa Indonesia". Jurnal KATA. Vol. 2 No. 2.

Paul, O. S. Herman, Ed. 2002. Sosiolinguistik. Jakarta: Kesain Blanc.

Rafiek, 2010. Teori Sastra Kajian teori dan praktik. Bandung: Refika Aditama.

Supriyanto, Aji. 2005. "Pengantar Teknologi Informasi”. Edisi Pertama. Penerbit Salemba Empat. Jakarta.

Trafena, Talika, F. 2016. "Manfaat Internet Sebagai Media Komunikasi Bagi Remaja Di Desa Air Mangga Kecamatan Laiwui Kabupaten Halmahera Selatan". Acta Diurna, Vol. 1. 